\title{
Taurodontism -A Review on its etiology, prevalence and clinical considerations
}

\author{
BS Manjunatha ${ }^{1}$, Suresh Kumar Kovvuru ${ }^{2}$ \\ ${ }^{1}$ BDS, MDS, (DNB), FAGE, Reader in Oral and Maxillofacial Pathology. Sumandeep Vidyapeeth. K M Shah Dental College \& \\ Hospital, Pipariya, 391760, Waghodia (T), Vadodara (D). Gujarat State, INDIA. \\ ${ }^{2}$ BDS, MDS, Assistant Professor. Department of Conservative Dentistry \& Endodontics. Sumandeep Vidyapeeth. K M Shah \\ Dental College \& Hospital, Pipariya, 391760, Waghodia (T), Vadodara (D). Gujarat State, INDIA.
}

Correspondence:

K M Shah Dental College \& Hospital,

Pipariya-391760, Waghodia (T), Vadodara (D)

Gujarat State, INDIA.

E-mail: drmanju26@hotmail.com

Manjunatha BS, Kovvuru SK. Taurodontism -A Review on its etiology, prevalence and clinical considerations. J Clin Exp Dent. 2010;2(4):e18790 .

http://www.medicinaoral.com/odo/volumenes/v2i4/jcedv2i4p187.pdf

Article Number: $50366 \quad$ http://www.medicinaoral.com/odo/indice.htm (C) Medicina Oral S. L. C.I.F. B 96689336 - eISSN: 1989-5488

eMail: jced@jced.es

\begin{abstract}
Taurodontism can be defined as a change in tooth shape caused by the failure of Hertwig's epithelial sheath diaphragm to invaginate at the proper horizontal level. An enlarged pulp chamber, apical displacement of the pulpal floor, and no constriction at the level of the cemento-enamel junction are the characteristic features. Although permanent molar teeth are most commonly affected, this change can also be seen in both the permanent and deciduous dentition, unilaterally or bilaterally, and in any combination of teeth or quadrants. Whilst it appears most frequently as an isolated anomaly, its association with several syndromes and abnormalities has also been reported. Despite the clinical challenges, taurodontism has received little attention from clinicians. Because of the prevalence of taurodontism in modern dentitions and the critical need for its true diagnosis and management, this review addresses the etiology, clinical and radiographic features of taurodontism, its association with various syndromes and anomalies, as well as important considerations in various areas of expertise dental treatments of such teeth.
\end{abstract}

Key words: Taurodontism, taurodont, Hertiwig's epithelial root sheath (HERS), bull teeth, enlarged pulp chamber. 


\section{Introduction}

Taurodontism is a morpho-anatomical change in the shape of the tooth in which the body of the tooth is enlarged and the roots are reduced in size. Taurodontism is recognized as a clinical entity for almost a century. Taurodontism has been found in the dentition of modern races. It is characterized by enlargement of the pulp chamber, which may approximate of the root apex, with the body of the tooth enlarged at the expense of the roots and apically displaced furcation areas (1). The bifurcation or bifurcation may be only a few millimeters above the apices of the roots. The dental literature on taurodontism is relatively sparse and most are case reports.

History

Taurodontism was first described in 1908 by Gorjanovic - Kramberger (2) a 70,000 year old pre-Neanderthal fossil, discovered in Kaprina, Croatia (3). Taurodontism was a frequent finding in early humans and is most common today in Eskimos, possibly as a selective adaptation for cutting hide (4). The term 'taurodontism' was however first stated by Sir Arthur Keith in 1913. The origin of this term is from Greek "tauros" which means "Bull" and "odontos" which means "Tooth" (5).

The literature contains reports of taurodontism with high frequency in Eskimos (6). Taurodontism has been found in the dentition of modern races. Shaw (7) reported the incidence to be as high as 30 per cent in hybrids of Australoids and the Bush people of South Africa. Taurodontism has been found in mongoloid and negroid populations (1).

It seems taurodontism is a great deal more prevalent than it was previously thought Seow and Lai found that $38.4 \%$ of 66 patients with hypodontia had atleast one mandibular first permanent molar that showed taurodontism compared with only $7.5 \%$ of a control group without hypodontia (8)

\section{Etiology and Pathogenesis}

Theories regarding the etiology of taurodontism have been many. It has been suggested that the anomaly represents a primitive pattern, a mutation, a specialized or retrograde character, an atavistic feature, an X-linked trait, familial or an autosomal dominant trait. Although taurodontism has been reported in association with certain syndromes and some genetic defects its true significance is still obscure (9).

Taurodontism appears most frequently as an isolated anomaly, but it has also been associated with several developmental syndromes and anomalies including amelogenesis imperfecta, Down's syndrome, ectodermal dysplasia, Klinefelter syndrome, tricho-dento-osseous syndrome, Mohr syndrome, Wolf-Hirschhorn syndrome and Lowe syndrome (10). Taurodontism has also been reported to present with other rare syndromes such as Smith-Magenis syndrome (11), Williams syndrome (12), McCune-Albright syndrome (13) and Van der Woude syndrome (14).

Theories concerning the pathogenesis of taurodontic root formation are also varied: an unusual developmental pattern, a delay in the calcification of pulpal chamber, an odontoblastic deficiency, an alteration in Hertwig's epithelial root sheath (15). According to some authors, taurodontism is most likely the result of disrupted developmental homeostasis (16).

\section{Classification}

In 1928 Shaw (7) classified this condition as hypotaurodontism, mesotaurodontism and hypertaurodontism based on the relative displacement of the floor of the pulp chamber. This subjective, arbitrary classification led normal teeth to be misdiagnosed as taurodontism.

In 1977, Feichfnger and Rossiwall (17) stated that the distance from the bifurcation or trifurcation of the root to the cemento-enamel junction should be greater than the occluso-cervical distance for a taurodontic tooth.

Though there are many classification systems to determine the severity of taurodontism, Shifman and Chanannel (18) in 1978 proposed a new classification and is the widely used system till now.

Prevalence

Review of the literature reveals a wide discrepancy in the prevalence of taurodontism in different populations. Its prevalence has been reported to range between $5.67 \%$ and $60 \%$ of subjects $(19,20)$. In a recent study, it has been accounted for $18 \%$ of all of the anomalies (21). The prevalence of taurodontism in children was found in $0.3 \%(22)$.

A study on a group of Jordanian dental patients has shown an overall prevalence of $8 \%$ for individuals (19). Ruprecht et al (23) found a prevalence of $11.3 \%$ for individuals in Saudi dental patients, whilst the results of Shifman and Channanel (18) were 5.6\% in Israeli dental patients, compared with $46.4 \%$ in young adult Chinese (24). These variations in prevalence between different populations may be due to ethnic variations, but may also be influenced by differences in criteria used for interpretation of taurodontism and also the specific teeth examined (17).

Some studies $(19,25)$ have included premolars, while others (23) believe that premolar teeth may not be affected by taurodontism. It is commonly observed among the Eskimos and Natives of Australia and Central America $(19,23,24)$

Radiographic features: Identification of the condition can only be made by radiographic examination as the external morphology of the teeth is within normal configurations.

The radiographic examination is the only way to visualize a rectangular configuration of the pulp chamber. Diagnosis of taurodontism has been based on subjective radiographic evaluation. Appearance of the taurodont tooth is very characteristic and the unusual nature of this 
condition is best visualized on the radiograph. Involved teeth assume a rectangular shape rather than tapering towards the roots. The pulp chamber is extremely large with a greater apico-occlusal height than normal and lacks the usual constriction at the cervical region of the teeth with exceedingly short roots. The bifurcation or trifurcation may be only a few millimetres $(\mathrm{mm})$ above the apices of the roots (26).

\section{Clinical Considerations}

The clinical implication of taurodontism has potentially increased risk of pulp exposure because of decay and dental procedures. Taurodontism may complicate orthodontic and/or prosthetic treatment planning. Taurodontism, although not very common has to be emphasized due to its influence on various dental treatments.

Endodontic considerations: A taurodont tooth shows wide variation in the size and shape of the pulp chamber, varying degrees of obliteration and canal configuration, apically positioned canal orifices, and the potential for additional root canal systems (27).

From an Endodontist's view, taurodontism presents a challenge during negotiation, instrumentation and obturation in root canal therapy. Because of the complexity of the root canal anatomy and proximity of buccal orifices, complete filling of the root canal system in taurodont teeth is challenging. A modified filling technique, which consists of combined lateral compaction in the apical region with vertical compaction of the elongated pulp chamber, has been proposed (28). In addition to the difficulty of the endodontic procedure, a recent case report suggests the possibility of taurodont teeth having an extraordinary root canal system which is challenging for endodontists (29).

Recently, a case report highlights the use of high-end diagnostic imaging modalities such as spiral computerized tomography in making a confirmatory diagnosis of the multiple morphologic abnormalities such as taurodontism, dens invaginatus, pyramidal cusps of the premolars, dens evaginatus (30).

The endodontic therapy of choice in these situations will be conservative. Therefore, root canal treatment becomes a challenge. Though taurodontism is of rare occurrence, the clinician should be aware of the complex canal system for its successful endodontic management.

Surgical considerations: The extraction of a taurodont tooth is usually complicated because of shift in the furcation to apical third (31). In contrast, it has also been hypothesized that the large body with little surface area of a taurodont tooth is embedded in the alveolus. This feature would make extraction less difficult as long as the roots are not widely divergent (27). It is reported that extraction of such teeth may not be a problem unless the roots are not widely divergent. However, some authors believe that hypertaurodonts may pose some problem during extraction because of apical shift of furcation and also due to difficulty in placement of forceps beaks. The authors believe that this problem can be resolved by proper usage of surgical tooth elevators.

Prosthetic considerations: For the prosthetic treatment of a taurodont tooth, it has been recommended that postplacement be avoided for tooth reconstruction (29). Because less surface area of the tooth is embedded in the alveolus, a taurodont tooth may not have as much stability as a cynodont when used as an abutment for either prosthetic or orthodontic purposes (27). The lack of a cervi $\neg$ cal constriction would deprive the tooth of the but $\neg$ tressing effect against excessive loading of the crown.

Periodontal considerations: From a periodontal standpoint, taurodont teeth may, in specific cases, offer favorable prognosis. Where periodontal pocketing or gingival recession occurs, the chances of furcation involvement are considerably less than those in normal teeth because taurodont teeth have to demonstrate significant periodontal destruction before furcation involvement occurs (26).

It is very important for a general dental practitioner to be familiar with taurodontism not only with regards to clinical complications but also its management. Taurodontism also provides a valuable clue in detecting its association with many syndromes and other systemic conditions.

\section{Summary and Conclusion}

From this review, it is apparent that taurodont teeth are presumed characteris $\neg$ tic of neanderthal man and are still present as a morphological entity in modern man. The occurrences, however, seem to have a biased racial expression in different populations. These variations in prevalence between different populations may be due to ethnic variations, but may also be influenced by differences in criteria used for interpretation of taurodontism and also the specific teeth examined.

This review attempts to address the etiology, radiographic features and clinical considerations in the treatment of such teeth. It can be seen that taurodontism has until now received insufficient attention from clinicians. No long-term follow-up studies have been published regarding treatment of taurodont teeth.

\section{References}

1. Mena CA. Taurodontism. Oral Surg Oral Med Oral Pathol. 1971;32:812-23.

2. Gorjanovic-Kramberger K. Über prismatische Molarwurzeln rezenter und diluvialer Menschen. Anat Anz. 1908;32:401-13.

3. Prakash R, Vishnu C, Suma B, Velmurugan N, Kandaswamy D. Endodontic management of taurodontic teeth. Indian J Dent Res. 2005; 16:177-81.

4. Coon CS. Origin of races. Science. 1963;140:208.

5. Witkop CJ. Clinical aspects of dental anomalies. Int Dent J. 1976;26:378-90. 
6. Goldstein E, Gottlieb MA. Taurodontism: familial tendencies demonstrated in eleven of fourteen case reports. Oral Surg Oral Med Oral Pathol. 1973;36:131-44.

7. Shaw JC. Taurodont Teeth in South African Races. J Anat. 1928;62:476-498.1

8. Seow WK, Lai PY. Association of taurodontism with hypodontia: a controlled study. Pediatr Dent. 1989;11:214-9.

9. Bhat SS, Sargod S, Mohammed SV. Taurodontism in deciduous molars - A case report. J Indian Soc Pedod Prev Dent. 2004;22:193-6.

10. Joseph M. Endodontic treatment in three taurodontic teeth associated with 48, XXXY Klinefilter syndrome: a review and case report. Oral Surg Oral Med Oral Pathol Oral Radiol Endod. 2008;105:670-7. 11. Tomona N, Smith AC, Guadagnini JP, Hart TC. Craniofacial and dental phenotype of Smith-Magenis syndrome. Am J Med Genet A. 2006;140:2556-61.

12. Axelsson S, Bjornland T, Kjaer I, Heiberg A, Storhaug K. Dental characteristics in Williams syndrome: a clinical and radiographic evaluation. Acta Odontol Scand. 2003;61:129-36.

13. Akintoye SO, Lee JS, Feimster T, Booher S, Brahim J, Kingman A et al. Dental characteristics of fibrous dysplasia and McCune-Albright syndrome. Oral Surg Oral Med Oral Pathol Oral Radiol Endod. 2003;96:275-82.

14. Nawa H, Oberoi S, Vargervik K. Taurodontism and Van der Woude syndrome. Is there an association? Angle Orthod. 2008;78:832-7.

15. Hamner JE 3rd, Witkop CJ Jr, Metro PS. Taurodontism; Report of A Case. Oral Surg Oral Med Oral Pathol. 1964;18:409-18.

16. Witkop CJ Jr, Keenan KM, Cervenka J, Jaspers MT. Taurodontism: an anomaly of teeth reflecting disruptive developmental homeostasis. Am J Med Genet Suppl. 1988;4:85-97.

17. Feichtinger C. Rosiwall B. Taurodontism in human sex chromosome aneuploidy. Arch Oral Biol.1977;22:327-9.

18. Shifman A, Chanannel I. Prevalence of taurodontism found in radiographic dental examination of 1,200 young adult Israeli patients. Community Dent Oral Epidemiol. 1978;6:200-3.

19. Darwazeh AM, Hamasha AA, Pillai K. Prevalence of taurodontism in Jordanian dental patients. Dentomaxillofac Radiol. 1998;27:163-5. 20. Rao A, Arathi R. Taurodontism of deciduous and permanent molars: report of two cases. J Indian Soc Pedod Prev Dent. 2006;24:42-4.

21. Guttal KS, Naikmasur VG, Bhargava P, Bathi RJ. Frequency of Developmental Dental Anomalies in the Indian Population. Eur J Dent. 2010;4:263-9.

22. Bäckman B, Wahlin YB. Variations in number and morphology of permanent teeth in 7-year-old Swedish children. Int J Paediatr Dent. 2001;11:11-7.

23. Ruprecht A, Batniji S, el-Newihi E. The incidence of taurodontism in dental patients. Oral Surg Oral Med Oral Pathol. 1987; 63:743-7.

24. Mac Donald-Jankowski DS, Li TT. Taurodontism in a young adult chinese population. Dento Maxillo Radiol. 1993;22:140-4.

25. Llamas R, Jimenez-Planas A. Taurodontism in premolars. Oral Surg Oral Med Oral Pathol 1993;75:501-5.

26. Shifman A, Buchner A. Taurodontism. Report of sixteen cases in Israel. Oral Surg Oral Med Oral Pathol. 1976;41:400-5.

27. Durr DP, Campos CA, Ayers CS. Clinical significance of Taurodontism. J Am Dent Assoc. 1980;100:378-81.

28. Tsesis I, Shifman A, Kaufman AY. Taurodontism: an endodontic challenge: report of a case. J Endod. 2003;29:353-5.

29. Bharti R, Chandra A, Tikku AP, Wadhwani KK. "Taurodontism" an endodontic challenge: a case report. J Oral Sci. 2009;51:471-4.

30. Metgud S, Metgud R, Rani K. Management of a patient with a taurodont, single-rooted molars associated with multiple dental anomalies: a spiral computerized tomography evaluation. Oral Surg Oral Med Oral Pathol Oral Radiol Endod. 2009;108:e81-6.

31. Yeh SC, Hsu TY. Endodontic treatment in taurodontism with Klinefelter's syndrome:a case report. Oral Surg Oral Med Oral Pathol Oral Radiol Endod.1999;88:612-5. 